\title{
Soluble Serum Transferrin Receptor (STFR) Levels in Hemodialysis Patients
}

\author{
Ayesha Majeed, ${ }^{1}$ Aisha Hameed, ${ }^{2}$ Iram Aftab, ${ }^{3}$ Muhammad Anees, ${ }^{4}$ Shahida Mohsin, ${ }^{5}$ Shabbir Hussain ${ }^{6}$
}

\begin{abstract}
Objectives: Anemia is a frequent disorder in patients with end-stage renal disease. Erythropoietin is advised in these patients; however, this therapy is not effective in patients who are iron deficient. So, diagnosis of iron deficiency which is traditionally based on ferritin and other iron parameters becomes difficult in these patients, as chronic kidney disease is a chronic inflammatory condition which affects these markers and masks the iron deficiency. In present study, we assessed the reliability of another indicator of body iron supply; serum transferrin receptor, in hemodialysis patients. It is not affected in case of inflammation unlike other markers of iron status.
\end{abstract}

Patients and Methods: Eighty Patients with end

${ }^{1}$ Hematology Department, University of Health Sciences

Lahore - Pakistan

${ }^{2}$ Assistant Professor, Pathology Department

Gujranwala Medical College, Gujranwala - Pakistan

${ }^{3}$ Consultant pathologist, DHQ Hospital

Sheikhupura - Pakistan

${ }^{4}$ Associate professor, Nephrology Department

King Edward Medical University, Lahore - Pakistan

${ }^{5}$ Professor, Hematology Department, University of Health Sciences, Lahore - Pakistan

${ }^{6}$ Senior Lab Manager, Biochemistry Department, University of Health Sciences, Lahore - Pakistan

Date of Submission: 9-5-2016

Date of Acceptance for Publication: 24-11-2016

Conflict of Interest: None

Funding Source: None

\section{Contribution}

All Authors have contributed in Study Design, Data Collection, Data Analysis, Data Interpretation, Manuscript Writing and Approval. stage renal disease, 20 to 60 years of age and both sexes were included. All cases were examined for complete blood count, serum iron, serum ferritin, serum total iron binding capacity, transferrin saturation and serum soluble transferrin receptor. Data was analysed by using independent sample $t$ test and Pearson' correlation. A $p$ value of $\leq 0.05$ was considered as significant.

Results: The results of our research showed that mean values of serum soluble transferrin receptor and serum ferritin were $3.28 \pm 0.83 \mu \mathrm{g} / \mathrm{ml}$ and $286.31 \pm 165$ $\mathrm{ng} / \mathrm{ml}$ respectively which were significantly higher than the upper normal limit $(p<0.001)$. Levels of sTfR were statistically different $(p=0.002)$ between iron replete group (SF $>100 \mathrm{ng} / \mathrm{ml}$ ) and iron deplete group ( $\mathrm{SF}<100 \mathrm{ng} / \mathrm{ml}$ ). Additionally, there was negative and significant correlation between STfR and Hemoglobin.

Conclusions: Levels of serum soluble transferrin receptor can be used as a reliable marker of iron deficiency in hemodialysis patients.

Key words: End-stage renal disease, anemia, hemodialysis, soluble Transferrin receptor.

\section{Introduction}

Chronic kidney disease (CKD) is the gradual, progressive deterioration of kidney function. Anemia is a well known complication of CKD, which may be due to insufficient erythropoietin or from iron deficiency as a result of inadequate absorption or mobilization. There should be proper balance between stimulating erythropoiesis and maintaining adequate iron levels for optimal red cell production in CKD patients. Erythropoietic stimulating agents (ESAs) mobilize iron stores to promote red cell production; however, low stores of iron or decreased iron availability are the main factors 
which resist the effect of ESAs. Iron management (iron status assessment and iron treatment), therefore, is crucial component for treating anemia associated with CKD. ${ }^{1,2}$

Exact estimation of the iron status in anemic patients who are on hemodialysis is fundamental to differentiate the patients who either suffer from absolute iron deficiency or have functional iron deficiency, which mainly limits the effect of rHuEPO therapy. There are many drawbacks of traditional laboratory biomarkers of iron status when used in CKD patients: CKD is a pro-inflammatory condition, and the biological variability of serum iron, transferrin saturation, and ferritin is known to be great because of the underlying inflammation by which not only, the clinical interpretation of their results is complicated but also wrong picture of the body iron status is created. ${ }^{3}$ In addition, bone marrow iron stores are often considered as the best indicator of iron status (although this is not generally accepted); however, bone marrow aspiration is invasive and not without risks e.g. infection or bleeding at the biopsy site. ${ }^{1}$

In search of a reliable indicator for assessing body iron supply, not affected by inflammatory procedures and pathologic conditions, serum soluble transferrin receptor (sTfR) was introduced. The TfR is a homodimeric trans membranous glycoprotein. It consists of 760 -amino-acids and is required for iron entry into the cells. sTfR measures the availability of iron in the bone marrow. When the bone marrow is stimulated by erythropoiesis stimulating agents (ESAs), it results in increased expression of transferrin receptors on the surface of erythroblasts, the precursors of RBC. If iron supply is low, then levels of transferrin containing iron are low, and there is a mismatch between the numbers of transferrin receptors and the transferrin-iron complexes to bind with them. Some of the transferrin receptors that are not bound by iron-containing transferring, then get detached and can be detected in the blood. Increased concentration of sTfRs in the blood is an indicator of iron deficiency.

Levels of sTfR may be helpful to differentiate between the anemia of chronic inflammation and anemia of iron deficiency as patients of CKD may have absolute or functional iron deficiency. ${ }^{4}$

\section{Materials and Methods}

It was a descriptive study. The study was approved by local ethical committee. It was conducted in the
Hematology Department, University of Health Sciences, Lahore. Eighty Patients from Shalamar Hospital Lahore with end stage renal disease (ESRD), 20 to 60 years of age and both sexes were included. They were on rHuEpo therapy for more than three months and undergoing maintenance hemodialysis treatment for more than six months twice weekly. Patients with bleeding, hemolytic anemia, liver diseases, infections, oral or intravenous iron and ascorbic acid supplementation were excluded. Written consent was taken from the patients.

Under aseptic conditions, $5 \mathrm{ml}$ of venous blood was collected from each subject by venipuncture and divided into two tubes. The first $2.0 \mathrm{ml}$ sample was transferred into a vaccutainer containing EDTA anticoagulant for complete blood count (CBC). The remaining $3.0 \mathrm{ml}$ blood was transferred into serum separateing tube (BD Vaccutainer SST) containing separation gel, and transported in a cool box to Department of Hematology, University of Health Sciences, Lahore. The collected blood samples in gel vaccutainers were centrifuged at a speed of 3400 revolutions per minute (RPM) for 5 minutes. The serum was then carefully shifted into aliquots and stored at $-20^{\circ} \mathrm{C}$. Serum Iron, Serum Total Iron Binding Capacity (TIBC) and Serum ferritin were measured according to standard laboratory methods. Serum Transferrin Receptors were measured by Biovender Human sTfR ELISA kiton Biorad680 Microplate reader.

The data was entered and analyzed by using SPSS version 20. Mean \pm SD were given for numeric variables while Frequency and percentages were for quailtative variables. Iron replete and iron deplete groups were compared by using independent sample ' $t$ ' test. Pearson' correlation coefficient was used for correlation analysis. A $p$ value of $\leq 0.05$ was considered as significant.

\section{Results}

Eighty patients of end-stage renal disease (ESRD) undergoing maintenance hemodialysis (MHD) treatment were included. Out of these 80 cases, males were $60 \%$ while females were $40 \%$ with mean age of 46.58 \pm 11.43 years. They were receiving recombinant human erythropoietin twice a week. Diabetes and hypertension were the commonest causes of CKD. Out of 80 patients, 31 were diabetic and 62 were hypertensive while only 2 and 4 were having glomerulonephritis and renal stones respectively. 
Mean $\pm \mathrm{SD}$, and range of hemoglobin, hematocrit, MCV, MCH, serum Transferrin Receptor, serum ferritin, serum iron, TIBC and TSAT are given in Table 1. The results showed that mean levels of sTfR and serum ferritin were $3.28 \pm 0.83 \mu \mathrm{g} / \mathrm{ml}$ and $286.31 \pm$ $165 \mathrm{ng} / \mathrm{ml}$ respectively. By applying one sample $t$-test, SF and sTfR levels were compared with their upper normal limits given by Mahdavi according to which the reference level for SF is $15-220 \mathrm{ng} / \mathrm{ml}$ and for sTfR is $1.0-2.9 \mu \mathrm{g} / \mathrm{ml}$ (Mahdavi et al., 2011). Mean levels of SF and STfR in HD patients were significantly higher than the upper normal limit $(p<0.001)$, (Fig. 1 and 2).

Table 1: Laboratory parameters of the study subjects.

\begin{tabular}{|l|c|c|c|}
\hline Variables & Mean \pm SD & Minimum & Maximum \\
\hline Hemoglobin $(\mathrm{g} / \mathrm{dl})$ & $9.62 \pm 2.00$ & 5.50 & 14.00 \\
\hline Hematocrit $(\%)$ & $29.03 \pm 6.19$ & 16.40 & 41.50 \\
\hline Mean cell volume of RBCs $(\mathrm{fl})$ & $88.35 \pm 6.43$ & 67.40 & 100.50 \\
\hline Mean cell hemoglobin of RBC) & $29.18 \pm 2.05$ & 22.00 & 33.80 \\
\hline Serum soluble transferrin receptor levels $(\mu \mathrm{g} / \mathrm{ml})$ & $3.28 \pm 0.83$ & 1.70 & 5.83 \\
\hline Serum ferritin levels $(\mu \mathrm{g} / \mathrm{l})$ & $286.32 \pm 165.16$ & 37.9 & 615.76 \\
\hline Serum Iron levels $(\mu \mathrm{g} / \mathrm{dl})$ & $64.72 \pm 32.21$ & 8.70 & 176.00 \\
\hline Total iron binding capacity $(\mu \mathrm{g} / \mathrm{dl})$ & $182.01 \pm 93.33$ & 43.80 & 438.60 \\
\hline Transferrin saturation $(\%)$ & $44.50 \pm 32.61$ & 4.76 & 223.74 \\
\hline
\end{tabular}

Data were given in Mean \pm SD with minimum and maximum values

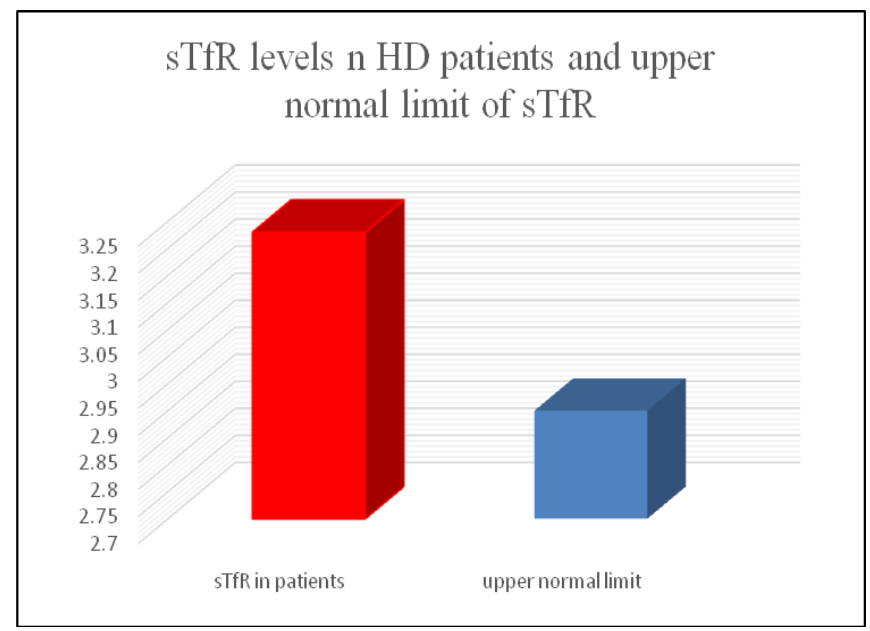

Fig. 1: Comparison of upper normal limit of serum transferring receptor levels in hemodialysis patients. Levels were significantly higher than the upper normal limit $(p<0.001)$.

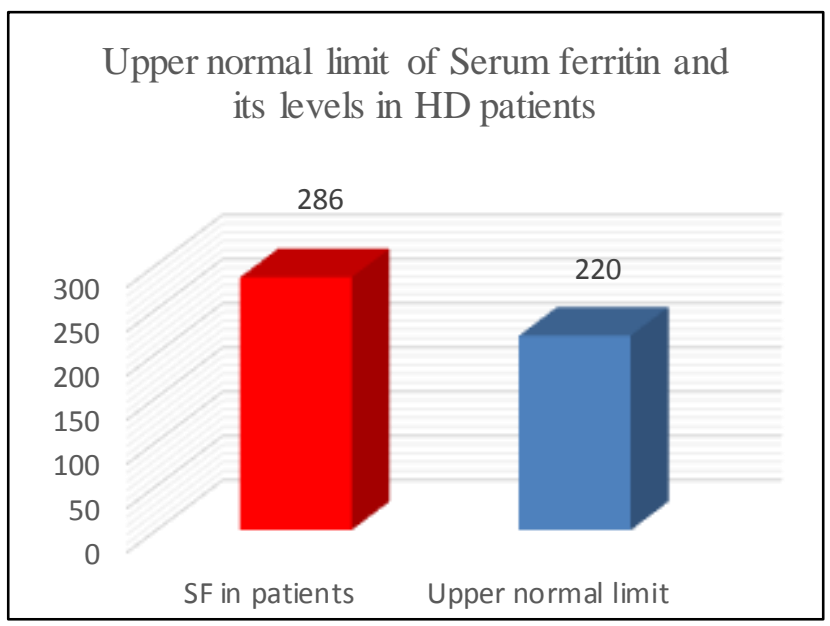

Fig. 2: Comparison of upper normal limit of serum ferritin $(S F)$ with hemodialysis patients. SF levels in HD patients were significantly higher than the upper normal limit ( $p<$ 0.001 ). 
Pearson's correlation demonstrated negative and significant correlation between sTfR levels and $\mathrm{Hb}$ and HCT. There were also negative but insignificant correlation between STfR and SF, TSAT and serum iron (Table 2). We divided our patients into three groups on the basis of hemoglobin levels $(<8,8-11,>11 \mathrm{~g} / \mathrm{dl})$. One way Anova demonstrated that sTfR levels were statistically different among the three groups $(p=$ $0.00)$.

The iron deficiency may be functional or absolute in patients of CKD. To differentiate between these, we made two groups of our patients i.e. iron deplete and iron replete group on the basis of serum ferritin with cut off level $100 \mathrm{ng} / \mathrm{ml}$ as per the guidelines of NKF / DOQI (Table 3). Independent sample $t$-test showed that sTfR levels were statistically and significantly different ( $p=0.002)$ among iron deplete group (SF < $100 \mathrm{ng} / \mathrm{ml}$ ) and iron replete group (SF $>100 \mathrm{ng} / \mathrm{ml}$ ).
Table 2: Correlation analysis of serum Transferrin receptor levels.

\begin{tabular}{|l|c|c|}
\hline \multicolumn{1}{|c|}{ Variables } & $\begin{array}{c}\text { r (Correlation } \\
\text { Value) }\end{array}$ & $\begin{array}{c}\text { P (Level of } \\
\text { Significance) }\end{array}$ \\
\hline Hemoglobin $(\mathrm{g} / \mathrm{dl})$ & -0.422 & $<0.001 *$ \\
\hline Hematocrit $(\%)$ & -0.426 & $<0.001 *$ \\
\hline $\begin{array}{l}\text { Serum Ferritin } \\
(\mathrm{ng} / \mathrm{ml})\end{array}$ & -0.082 & 0.468 \\
\hline Srum Iron $(\mu \mathrm{g} / \mathrm{dl})$ & -0.022 & 0.070 \\
\hline $\begin{array}{l}\text { Transferrin Saturation } \\
(\%)\end{array}$ & -0.144 & 0.203 \\
\hline
\end{tabular}

*statistically significant

Table 3: Comparison of sTfR levels in patients of two groups.

\begin{tabular}{|l|c|c|c|}
\hline & $\begin{array}{c}\text { Iron Replete Group } \\
(\mathbf{S F}>\mathbf{1 0 0} \mathbf{~ n g} / \mathbf{m l})\end{array}$ & $\begin{array}{c}\text { Iron Deplete Group } \\
(\mathbf{S F}<\mathbf{1 0 0} \mathbf{~ n g} / \mathbf{m l})\end{array}$ & p-value \\
\hline No of patients & $59(73.75 \%)$ & $21(26.25 \%)$ & \\
\hline Mean sTfR $(\mu \mathrm{g} / \mathrm{ml})$ & $3.11 \pm 0.68$ & $3.76 \pm 1.03$ & $0.002^{*}$ \\
\hline
\end{tabular}

*statistically significant

\section{Discussion}

Hemodialysis patients who are on rHuEpotherapy, commonly suffer from iron deficiency anemia which may be either functional or absolute. So, it becomes difficult to differentiate between these two conditions. The aim of our research was to assess the soluble transferrin receptor levels and to ascertain the role of sTfR as a marker of iron deficiency anemia in the patients of CKD undergoing hemodialysis.

In our study subjects, anemia was quiet prevalent and was found to be $83.75 \%$. Some previous studies have shown higher prevalence of anemia in their study population. ${ }^{4,5}$ Mean hemoglobin in our CKD patients was $9.62 \pm 2.00 \mathrm{~g} / \mathrm{dl}$. There are also discrepancies related to the values of hemoglobin in different studies. A study which was carried out in India has observed lower values of the mean hemoglobinin CKD patients. ${ }^{6}$ While slight elevation of hemoglobin concentration has been reported in two other studies. ${ }^{7,8}$ The low levels of hemoglobin in our patients may be due to the malnutrition as most of the patients belonged to the lower economic status. Another reason of low hemoglobin may be hyporesponsiveness to erythropoietin. Many factors are responsible for hyporesponsiveness to erythropoietin which may include iron deficiency, inflammation or infection, chronic blood loss, deficiencies of vitamins, inadequate dialysis, hyperparathyroidism and malignancy.

In our study, correlation analysis showed that STfR levels are negatively correlated with hemoglobin and hematocrit $(p<0.01)$. Similar findings have been reported by some other studies, ${ }^{4,9}$ while a study which was conducted in Taiwan found positive correlation of sTfR with hemoglobin and hematocrit. ${ }^{10}$ A positive correlation has also been suggested by Lorenzo. ${ }^{11}$ Additionally, our patients were classified into three groups on basis of hemoglobin and it was noticed that levels of STfR were statistically different between three groups. Highest values of sTfR were found in the 
group with lowest hemoglobin. So, we may suppose that as patient's hemoglobin falls, it results in increased expression of sTfR on developing erythroblasts to promote iron entry and consequently red cell production.

In current study, mean serum ferritin values were found to be elevated as compared to upper normal limit $(p<0.01)$. Another study by Gupta et al, also observed higher values of mean serum ferritin. ${ }^{4}$ This observation points that serum ferritin is not a good indicator of iron deficiency in end-stage renal disease because it is an acute phase reactant and it is increased in inflammatory diseases e.g. chronic kidney disease. So, SF values do not tell us about accurate status of body iron supply. ${ }^{12}$

Measurement of sTfR levels and its utility to detect deficiency of iron in patients of end stage renal disease has been studied in some previous investigations. Whenever, there is decreased intracellular iron, it results in increased synthesis of TfR so that iron uptake into the cell may increase. In present study, the mean sTfR values were $3.28 \pm 0.83 \mu \mathrm{g} / \mathrm{ml}$ which were higher as compared to the reference range $(p<0.01)$. Same finding has been suggested in a previous study. ${ }^{4}$ Another study found no significant difference in values of sTfR between anemic controls and patients of hemodialysis $(p=0.69)$. So it was concluded that same values of sTfR in non-uremic iron deficient patients and hemodialysis patients may be regarded as an indicator of iron deficiency present in the latter group. ${ }^{12}$ In another study, it was reported that patients of iron deficiency anemia who had chronic diseases were having higher values of sTfR as compared to anemic patients suffering from chronic diseases but with normal iron storage. This observation favours the usefulness of sTfR as a marker to differentiate between anemia of chronic disease and anemia of iron deficiency. ${ }^{13}$

In our study, it was noticed that STfR levels were inversely correlated to SF, iron and TSAT but it was statistically insignificant. These results are in accordance with another study. ${ }^{4}$ Whereas, Tarng and Huang suggested that STfR values were negatively correlated to SF and TSAT and it was statistically significant. ${ }^{14}$ On contrary, Beerenhout et al noticed that sTfR and SF were not related. ${ }^{15}$

Another factor which might favour that STfR is a better indicator of iron deficiency in patients of chronic kidney disease was that, sTfR values were lower $(3.11 \pm 0.68 \mu \mathrm{g} / \mathrm{ml})$ in iron replete group (SF > 100 $\mathrm{ng} / \mathrm{ml}$ ) in comparison with the iron deplete group (3.76 $\pm 1.03 \mu \mathrm{g} / \mathrm{ml}$ ) and this difference was found to be statistically significant $(p=0.002)$ between these groups. Our results are different from that observed by Gupta et al., 2009.

In this study, it was seen that sTfR can differentiate between two separate conditions like iron deficiency anemia and anemia of chronic disease which may present together in CKD patients. Therefore, physicians have to face difficulties in diagnosis of iron deficiency in the presence of a chronic disorder: STfR is an appropriate tool to detect iron deficiency, despite the presence or absence of inflammatory disease, and high values of SF suggest ongoing inflammation. Therefore, we can collectively use the results of sTfR and SF to assess iron deficiency as well as inflammation.

\section{Conclusion}

STfR is a good marker to differentiate between absolute and functional iron deficiency. sTfR levels can also be raised in case of accelerated iron deficient erythropoiesis in HD patients due to rHuEpo therapy. So it is concluded that sTfR can be used to monitor iron status in HD patients if rHuEpo doses are maintained.

\section{References}

1. Chung M, Moorthy D, Hadar N, Salvi P, Iovin RC, Lau J. Biomarkers for Assessing and Managing Iron Deficiency Anemia in Late-Stage Chronic Kidney Disease. Comparative Effectiveness Review No. 83. Rockville (MD): Agency for Healthcare Research and Quality (US), 2012; Oct. Report No: 12 (13) - EHC140-EF.

2. National Kidney Foundation:Kidney disease outcome quality initiative (KDOQI). Anemia and chronic kidney disease, 2007.

3. Vanrenterghem Y, Ponticelli C, Morales JM, Abramowicz D, Baboolal K, Eklund B, et al. Prevalence and management of anemiain renal transplant recipients: a European survey. Am J Transplant. 2003; 3 (7): 835-45.

4. Gupta S, Uppal B, Pawar B. Is soluble transferrin receptor a good marker of iron deficiency anemia in chronic kidney disease patients? Indian J Nephrol, 2009; 19: 96-100.

5. Talwar VK, Gupta HL, Shashinarayan. Clinicohaematological profile in chronic renal failure. J Assoc Physician India, 2002; 50: 228-33.

6. Sing NP, Aggarwal L, Singh T, Anuradha S, Kohli R. Anemia, iron studies and erythropoietin in patients of chronic renal failure. JAPI. 1999; 47: 284-90.

7. Braun J, Lindner K, Schreiber M, Heidler RA, Horl WH. Percentage of hypochromic red blood cells as predictor of erythropoietic and iron response after i.v. iron 
supplementation in maintenance of hemodialysis patients. Nephrol Dial Transplant. 1997; 12: 1173-81.

8. Fusaro M, Munaretto G, Spinello M, Rebeschini M, Amici G, Gallieni M, et al. Soluble transferrin receptors and reticulocytes hemoglobin concentration in the assessment of iron deficiency in hemodialysis patients. J Nephrol. 2005; 18: 72-9.

9. Tonbul HZ, Kaya H, Selcuk NY, Tekin SB, San A, Aknay $\mathrm{F}$, et al. The importance of serum transferrin receptor level in diagnosis of functional iron deficiency due to recombinant human erythropoietin treatment in haemodialysis patients. Int Urol Nephrol. 1998; 30: 645-51.

10. Chiang WC, Tsai TJ, Chen YM, Lin SL, Hsieh BS. Serum soluble transferrin receptor reflects erythropoiesis but not iron availability in erythropoietin-treated chronic hemodialysis patients. Clin Nephrol. 2002; 58 (5): 363-9.

11. Lorenzo JD, Rodriguez MM, Martin SS, Romo JM. Assessment of erythropoiesis activity during hemodialysis therapy by soluble transferrin receptor levels and ferrokinectic measurement. Am J Kidney Dis. 2001; 37: 550-6.

12. Mahdavi MR, Makhlough A, Kosaryan M,Roshan P. Credibility of the measurement of serum ferritin and transferrin receptor as indicators of iron deficiency anemia in hemodialysis patients. Eur Rev Med Pharmacol Sci. 2011; 15: 1158-62.

13. Keskin T, Hurmeydan O, Onder Y, Dagdelen L, Caner $\mathrm{N}$, Yucel N, et al. The value of soluble transferring receptor and Tfr-Ferritin index in the differential diagnosis of iron deficiency anemia. Clin Biochem. 2009; 42: 343-44.

14. Tarng DC, Huang TP. Determinants of circulating soluble transferrin receptor level in chronic haemodialysis patients. NDT. 2002; 17 (6): 1063-69.

15. Beerenhout C, Bekers O, Kooman JP, Van Der Sande FM, Leunissen KM. A comparison between the soluble transferrin receptor, transferritin saturation and serum ferritin as markers of iron state in hemodialysis patients. Nephron. 2002; 92: 32-35. 